\title{
Comparative Evaluation of Bactericidal, Antifungal And Antioxidant Properties of Biologically Active Schiff Bases of Substituted Indoles And Their Inclusion Complexes With $\square$-CD
}

\author{
Pramoda Kumar Das ${ }^{1}$, Rabinarayana Sahu $^{2} *$ Bamakanta Garnaik $^{3}$ \\ P. G. Department Of Chemistry, Berhampur University, Bhanja Bihar,760007 \\ Odisha, India
}

\begin{abstract}
Schiff bases having indole moiety are well known biological active agents. The present research deals with the preparation of 5-substituted furan-2-yl) [1,3,4] thiadiazino[6,5b]indole-3-amine from 2-amino 1,3,4-thiadiazino[6,5b] indole and sustituted furfural. In aqueous medium the compounds are less soluble, which causes diminishing biofunctionality. The bioaccessibility and stability of the synthesized schiff bases can be enhanced by the preparation of their inclusion complexes with $\beta$-Cyclodextrin. The Schiff bases as well as their inclusion complexes are analyzed through physical and different spectral techniques like UV-visible, FT$I R,{ }^{l} H$ NMR'. Thermodynamic properties like change in free energy and stability constant of the inclusion complexes have been ascertained which gives an essential information about their stability. The compounds and their inclusion complexes are also investigated against S.aureus, P.vulgaris, B.subtilis and E.coli. The antifungal activity of the Schiff bases and their inclusion complexes are also verified by considering three fungal organisms i.e A.Fumigatus, A.Niser and C.Albicans. The free radical trapping tendency is also studied. The encapsulation of the Schiff base in the core of $\beta$-cyclodextrin enhances antibacterial, antifungal and antioxidant properties.
\end{abstract}

Keywords: antibacterial activity, antifungal activity,antioxidant activity, Inclusion complex, substituted indoles, $\beta$-cyclodextrin, ,

\section{Introduction}

Five membered heterocycles and their derivatives have attracted the attention of chemists mainly because of their manifold applications in pharmaceuticals. Schiff bases having indole moiety as active core have considered as versatile pharmacophores because they possess effective pharmacological activities such as antiviral[1], antibacterial[2], anti-inflammatory[3-4], antifungal[5], antioxidant[6], anti-tubercular[7], anticancer[8] etc.

In a successful attempt, Schiff bases of substituted furfuraldehyde were prepared first by condensing isatin with thiosemicarbazide to give an intermediate 2 -amino-1,3,4-thiadiazino[6,5b] indole and then by condensing the intermediate with methyl furfural and nitro furfural[9]. The sparingly soluble property of synthesized compounds in aqueous medium reduces its pharmaceutical activities. Hence the synthesized compounds are entrapped into the core of $\beta$-cyclodextrin to improve their solubility and stability[10-11]. The $\beta$ $\mathrm{CD}$ is used mainly due to its structural aspects i.e. hydrophilic outer and hydrophobic interior[12].The hostguest stoichiometry of the complex has been ascertained from the curves of phase solubility studies of the compounds. The change in free energy and stability constant of the inclusion complexes have been determined which reveals that the formation of inclusion complexes is thermodynamically acceptable [13].

The research work aims to investigate a comparative study of antibacterial, antifungal and antioxidant properties of the synthesized pharmaceutically active compounds and their inclusion complexes.So the schiff base and its inclusion complex with $\beta$-cyclodextrin are screened against some gram $+v e$ and gram -ve bacterial strain such as E.Coli, Bacillus subtilis, P.Vulgaris and Staphylococcus aureus. The fungal strains such as A.Fumigatus, A.Niser and C.Albicans are examined for compounds and their complexes by food poisoned method. Further they are subjected to antioxidant property investigation by using DPPH .The study demonstrates the fact that the inclusion complexes exhibit remarkable antibacterial, antifungal and antioxidant behavior as compared to their respective compounds, this may be due to improved solubility and significant stability of the complex compounds. 


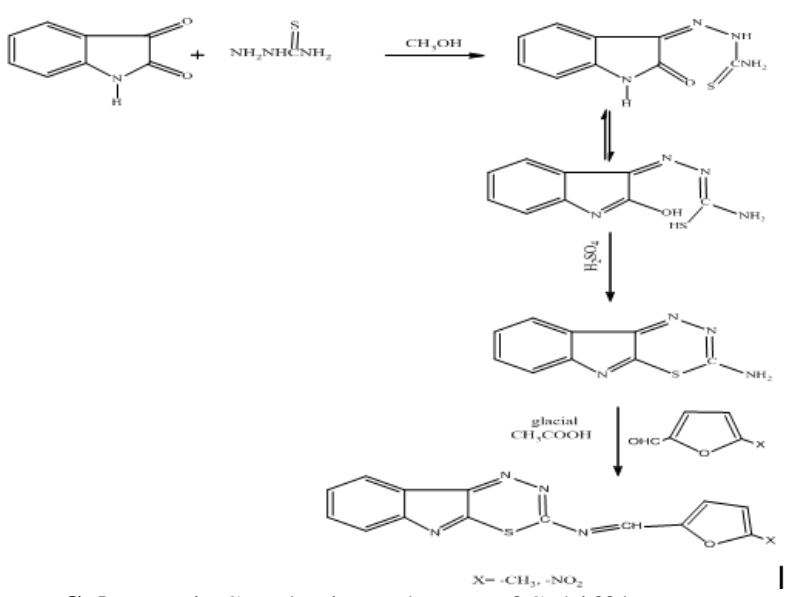

Scheme 1: Synthetic pathway of Schiff bases

Compound K= E-N-((5-methylfuran-2-yl) methylene) [1,3,4]- thiadiazino [6 5 b] indol-3-amine

Compound $\mathrm{L}=\mathrm{N}$ - ((5-Nitro furan-2-yl)methylene) [1,3,4]- thiadiazino [6,5b] indol-3-amine

\subsection{Apparatus and Chemicals}

\section{Materials and Methods}

5-methyl furfural and 5- nitro furfural are purchased from Sigma Aldrich Chemical Company and used as such. All other chemicals and solvents used are of the highest grade and are purchased from the local market. Double distilled water is prepared in the laboratory and is used for the preparation of aqueous solutions. Purity of the compounds is checked by its sharp melting point. U.V Spectra are taken with the help of Shimadzu- 1800 Spectrophotometer and I.R spectra are recorded on Shimadzu-8400 FTIR Spectrophotometer using KBr pellets. ${ }^{1} \mathrm{H}$ NMR spectra in $\mathrm{CDCl}_{3}$ are recorded on Bruckers spectrophotometer model ultra shield at $300 \mathrm{MHz}$ using TMS as internal standard.

2.2 Synthesis of E-N-((5-methyl furan-2-yl) methylene) [1,3,4] - thiadiazino[6,5 b] indol-3-amine: The synthesis of the above titled compound (Schiff's base- K) involves following three intermediate steps.

2.2.1Step-1: Synthesis of 3- Thiosemicarbazido indol-2-one Equimolar mixture (0.013 mole) of Isatin and thiosemicarbazide are taken in a $500 \mathrm{ml}$ round bottomed flask. The refluxation of the mixture is carried out in methanol for about one hour. The completion point of the reaction is verified through TLC technique. The excess of the solvent is distilled out and the contents are cooled. The cooled content is poured into ice cold water which gives a precipitate. The precipitate is filtered through whattman 42 filter paper. The residue is washed with distilled water, it is dried and recrystallised from $\mathrm{CH}_{3} \mathrm{OH}$ to obtain 3- thiosemicarbazido indol -2 one.Percentage of yield is $80 \%$ and the mp is $235^{\circ} \mathrm{C}$.

\subsubsection{Step-2: Synthesis of 2- amino $-\mathbf{1 , 3 , 4}$-Thiadiazino [6 $5 \mathrm{~b}$ ] indole.}

0.0136 mole of 3-Thiosemicarbazido indol 2- amine is mixed with small quantity of cold conc. $\mathrm{H}_{2} \mathrm{SO}_{4}$ in a beaker. The beaker containing the mixture is kept undisturbed for 16 hours at room temperature. Then ice cold water is poured into the reaction mixture. It is neutralised with few drops of liquid ammonia to get a solid mass. It is filtered through whattman 42 filterpaper. The residue is washed with distilled water. The dried residue is recrystallised from ethanol to give 2- amino -1,3,4-Thiadiazino $[6,5 \mathrm{~b}]$ indole. Percentage of yield is $65 \%$ and $\mathrm{mp}$ is $220^{\circ} \mathrm{C}$.

\subsubsection{Step-3: Synthesis of E-N-((5-methylfuran-2-yl) methylene) $[1,3,4]$ - thiadiazino $[6,5$ b] indol-3- amine.}

$1 \mathrm{ml}(0.01 \mathrm{~mole})$ of 5-methylfurfural and 0.01 mole of 2-amino-1.3.4- thiadiazino [6 $5 \mathrm{~b}$ ] indole are taken in $50 \mathrm{ml}$ DMF. To it few drops of glacial aceticacid is added and the mixture is refluxed for 6 hours. The completion of the reaction is checked by TLC and excess of the solvent is distilled out. The solution is cooled.To the clear solution some crushed ice are added to get a solid product. It is filtered, washed with distilled water and dried. The crude product is recrystallised from absolute alcohol to give the pure compound.

By following the same procedure another Schiff's base of substituted indole i.e N- ((5-Nitro furan-2yl)methylene) [1,3,4]- thiadiazino [6,5b] indol-3-amine (compound- L) is synthesized by taking equimolar mixture (0.01 mole) of 5- Nitro furfural and 2-amino-1,3,4- thiadiazino [6,5b] indole. 


\subsection{Phase Solubility Measurements:}

The solubility of the compound in aqueous phase at various concentrations of $\beta$-cyclodextrin $(0-7 \mathrm{mMl})$ is studied by a method suggested by Higuchi-Conner[14].

\subsection{Synthesis of inclusion complexes:}

Among various methods, co-precipitation method[15] is chosen for the synthesis of inclusion complexes of the compounds $(\mathrm{K}, \mathrm{L})$. With the constant molar concentration of the compounds, different molar concentrations of $\beta$-cyclodextrin are added. For a period of 48 hours, the mixtures are stirred by a magnetic stirrer and then they are filtered through whatmann 42 filter papers. The filtrates are cooled for 24 hours in refrigerator. The precipitates obtained are filtered through G-4 crucible, washed with distilled water and dried in air for 24 hours.

\subsection{Study of thermodynamic properties:}

The stability constants of the complexes $(\mathrm{K}$ and $\mathrm{L})$ are calculated from plots of inverse of change in absorbance versus inverse concentration of $\beta$-cyclodextrin using Benesi-Hilderband relation[16].

$$
\left.1 / \Delta \mathrm{A}=1 / \Delta \varepsilon+1 / \mathrm{K}_{\mathrm{T}}[\text { Guest }]_{\mathrm{o}} \text {.[ } \beta-\mathrm{CD}\right]
$$

where $\Delta \mathrm{A}$ is change in absorbance, $\Delta \varepsilon$ is change in absorption coefficient, $\mathrm{K}_{\mathrm{T}}$ is stability constant, [Guest $]_{\mathrm{o}}$ is the concentration of compound and $[\beta-\mathrm{CD}]$ is the concentration of $\beta$-cyclodextrin. The values of stability constants for all the complexes are calculated using the relation

Stability Constant $\left(\mathrm{K}_{\mathrm{T}}\right)=$ Intercept/Slope

The value of $\Delta \mathrm{G}$ at $298 \mathrm{~K}$ is calculated by using the equation:

$\Delta \mathrm{G}=-\mathrm{RT} \ln \mathrm{K}_{\mathrm{T}}$, where $\mathrm{K}_{\mathrm{T}}$ is the stability constant.

\subsection{Antibacterial study:}

As per cup-plate method [17-18] the antibacterial activity of compounds is carried out. Dimethyl sulphoxide (DMSO) at $500 \mu \mathrm{g} / \mathrm{mL}$ is taken and solutions of synthesized compounds and inclusion complex are prepared with a conc. of $500 \mu \mathrm{g} / \mathrm{mL}$. Four types of bacteria namely E. coli, S. aureus, B.Subtilis and P. vulgaris are injected into $100 \mathrm{~mL}$ of the sterile nutrient broth and this is subjected to incubation at about $37^{\circ} \mathrm{C}$ for a period of $24 \mathrm{hrs}$. Agar plates with uniform diameters are used to vaccinate them one by one with the test organisms aseptically. With the help of micropipette, drug and test compounds solution are taken and then plates are placed in the refrigerator at $8-10{ }^{\circ} \mathrm{C}$ for right dispersal of drug into the media. The Petri plates are transferred to incubator after $2 \mathrm{hrs}$ and maintained a temperature of nearly $38^{\circ} \mathrm{C}$ for $22 \mathrm{hrs}$. Zone of inhibition of the Petri plates are determined by using vernier scale and the data are interpreted.

\subsection{Evaluation of Antifungal activity:}

The antifungal effect against molds is investigated by Poisoned food method[19]. The synthesized compound is incorporated into the molten potato dextrose agar in a required concentration and it is autoclaved for 15 mins at $15 \mathrm{lbs}$ pressure. In different petridishes, the medium is poured. The inoculation of fungus is done in specified petridishes and it is incubated at $37^{\circ} \mathrm{C}$ for overnight. After incubation under favorable conditions for the fungal strain tested, the diameters of fungal growth in control (zone of inhibition)and sample plates are measured, and the efficacy of the synthesized Schiff bases against antifungal activity is estimated.

\subsection{Evaluation of Antioxidant activity:}

The screening of the antioxidant activities of the synthesized compounds and their complexes are carried out by DPPH scavenging assay method, suggested by Tagashira and Ohtake[20]. In the prepared ethanolic solution of DPPH, the test sample $(100 \mu \mathrm{g} / \mathrm{ml})$ with required concentration is mixed . The above formed mixture is incubated for 20 minutes at $27^{\circ} \mathrm{C}$ and the absorbance at $517 \mathrm{~nm}$ is measured. The difference in absorbance between a test sample and a control is considered as activity. Ascorbic acid is used as standard of reference.

\section{Results and Discussions}

Schiff bases of methyl (compound K) and nitro (Compound L) substituted furfuraldehyde are synthesized in their crystalline solid forms. The maximum encapsulation conc. of $\beta$-cyclodextrin has been determined from aqueous phase solubility study (fig.1). The inclusion complexes of the synthesized bioactive Schiff bases having indole moiety are prepared with $\beta$-cyclodextrin. The structures of the compounds $(\mathrm{K}$ and $\mathrm{L})$ and their inclusion complexes have been elucidated from physical properties (Table 2), elemental composition and spectral data such as UV, IR and ${ }^{1} \mathrm{H}$ NMR

( Table 3). The composition of elements present in the compounds derived through CHN analyser resembles with theoretical data (Table-1). 
Table 1: Elemental Composition of the compounds

\begin{tabular}{|c|c|c|c|c|c|}
\hline \multirow{2}{*}{ Compound } & \multicolumn{5}{|c|}{ Elemental Analysis } \\
\cline { 2 - 6 } & $\mathrm{C}$ & $\mathrm{H}$ & $\mathrm{N}$ & $\mathrm{S}$ & $\mathrm{O}$ \\
\hline \multirow{2}{*}{$\mathrm{K}$} & 48.38 & 32.25 & 12.90 & 3.22 & 3.22 \\
& $(48.42)$ & $(32.16)$ & $(12.85)$ & $(3.12)$ & $(3.13)$ \\
\hline \multirow{2}{*}{$\mathrm{L}$} & 46.66 & 23.33 & 16.66 & 3.33 & 10.00 \\
& $(46.34)$ & $(23.25)$ & $(16.56)$ & $(3.19)$ & $(10.09)$ \\
\hline
\end{tabular}

An increased melting point of inclusion complexes of respective compounds may be featured through the fact that an additional thermal energy is required for deencapsulation from the $\beta$-cyclodextrin cavity (Table 2). The IR frequency data 746 (C-Sstr.), 1211(C-N str.), 1338 (C-O str.),1471, 1541, 1616 (Ar., C=C str.), 1714 $(\mathrm{C}=\mathrm{N}$ str.), 3041(C-H str. Furfural) confirms the presence of these groups in the compound. There is a remarkable change in the IR data in all compounds after encapsulation (absorption frequencies shift towards higher energy side) which is featured to the fact that there are some weak interactions within the hydrophobic cage of $\beta$-cyclodextrin(Table-3). The host-guest complexation is further supported by NMR data (Table-3). The NMR signals of different protons of the compounds are recorded before and after encapsulation. It is observed that all the protons undergo smaller shifts (towards upfield in case of all the compounds) after encapsulation. These shifts can be explained on the basis of shielding phenomena which arise due the caging of the protons in the core of $\beta$-cyclodextrin.

Table 2 : Some physical properties of the synthesized compounds and complexes

\begin{tabular}{|c|c|c|c|c|c|c|}
\hline $\begin{array}{l}\text { Sl } \\
\text { No. }\end{array}$ & $\begin{array}{l}\text { Compound/ } \\
\text { Complex }\end{array}$ & Molecular formula & $\begin{array}{c}\text { Molecul } \\
\text { ar } \\
\text { weight }\end{array}$ & Colour & $\begin{array}{l}\text { M.P. } \\
\left({ }^{0} \mathrm{C}\right)\end{array}$ & $\begin{array}{c}\text { Yield( } \\
\%)\end{array}$ \\
\hline \multirow[t]{2}{*}{1} & Compound- K & $\mathrm{C}_{15} \mathrm{H}_{10} \mathrm{~N}_{4} \mathrm{OS}$ & 294 & Light brown & $110-115$ & 78 \\
\hline & I.C.K & & & white & $260-265$ & 73 \\
\hline \multirow[t]{2}{*}{2} & Compound- L & $\mathrm{C}_{14} \mathrm{H}_{7} \mathrm{~N}_{5} \mathrm{O}_{3} \mathrm{~S}$ & 325 & Pale yellow & $80-85$ & 70 \\
\hline & I.C.L & & & Dull white & $270-275$ & 75 \\
\hline
\end{tabular}

Table 3: Spectral data of synthesized compounds and complexes

\begin{tabular}{|c|c|c|c|c|}
\hline $\begin{array}{c}\text { Sl } \\
\text { No. } \\
\end{array}$ & $\begin{array}{c}\text { Compound/ } \\
\text { Inclusion }\end{array}$ & $\begin{array}{c}\mathrm{UV} \\
\lambda_{\mathrm{Max}}(\mathrm{nm})\end{array}$ & $\mathrm{IR}(\mathrm{KBr}) \mathrm{cm}^{-1}$ & NMR \\
\hline 1 & Compound K & 349 & $\begin{array}{c}746 \text { (C-Sstr.), } 1211 \text { (C-N str.), } 1338 \text { (C-O str.) } \\
1471,1541,1616 \text { (Ar., C=C str.), } 1714 \text { (C=N } \\
\text { str.), } 3041 \text { (C-H str. Furfural) }\end{array}$ & $\begin{array}{c}{ }^{1} \mathrm{H} \mathrm{NMR}\left(\mathrm{CDCl}_{3}\right): \delta \\
6.05-7.7(\mathrm{~d}, 4 \mathrm{H}, \mathrm{Ar}-\mathrm{H}), \\
6.9-7.3(\mathrm{~m}, 2 \mathrm{H}, \mathrm{Ar}- \\
\mathrm{H}), 7.6(\mathrm{~s}, 1 \mathrm{H}, \mathrm{N}-\mathrm{CH}), 2.4 \\
\quad\left(\mathrm{~m}, 3 \mathrm{H}, \mathrm{CH}_{3}\right)\end{array}$ \\
\hline 2 & Inclusion $\mathrm{K}$ & 353 & $\begin{array}{c}754 \text { (C-S str.), } \begin{array}{c}1215(\mathrm{C}-\mathrm{N} \text { str. }), 1338 \text { (C-O } \\
\text { str.) }\end{array} \\
1471,1539,1651 \text { (Ar., C=C str.), } 1732(\mathrm{C}=\mathrm{N} \\
\text { str.) } 3371 \text { (H-bonding with } \beta-\mathrm{CD})\end{array}$ & $\begin{array}{c}{ }^{1} \mathrm{H} \text { NMR }\left(\mathrm{CDCl}_{3}\right): \delta \\
6.05-7.7(\mathrm{~d}, 4 \mathrm{H}, \mathrm{Ar}-\mathrm{H}), \\
6.9-7.3(\mathrm{~m}, 2 \mathrm{H}, \mathrm{Ar}- \\
\mathrm{H}), 7.6(\mathrm{~s}, 1 \mathrm{H}, \mathrm{N}-\mathrm{CH}), 2.4 \\
\quad\left(\mathrm{~m}, 3 \mathrm{H}, \mathrm{CH}_{3}\right)\end{array}$ \\
\hline 3 & Compound L & 351 & $\begin{array}{c}744 \text { (C-Sstr.), 1203(C-N str.), } 1338 \text { (C-O str.) } \\
\text { 1471, 1541, 1614(Ar., C=C str.), } 1714 \text { (C=N } \\
\text { str.), 3194(C-H strl. Furfural) }\end{array}$ & $\begin{array}{c}{ }^{1} \mathrm{H} \mathrm{NMR}\left(\mathrm{CDCl}_{3}\right): \delta \\
6.9-7.8(\mathrm{~d}, 4 \mathrm{H}, \mathrm{Ar}-\mathrm{H}) \\
\text { 7.3-7.6(m,2H, Ar- } \\
\mathrm{H}), 7.6(\mathrm{~s}, 1 \mathrm{H}, \mathrm{N}-\mathrm{CH})\end{array}$ \\
\hline 4 & Inclusion L & 354 & $\begin{array}{c}\text { 752(C-Sstr.), } 1214 \text { (C-N str.), } 1339 \text { (C-O str.) } \\
\text { 1471, 1538, } 1616 \text { (Ar., C=C str.), } 1728(\mathrm{C}=\mathrm{N} \\
\text { str.), 3368(H-bonding with } \beta-\mathrm{CD})\end{array}$ & $\begin{array}{c}{ }^{1} \mathrm{H} \text { NMR }\left(\mathrm{CDCl}_{3}\right): \delta \\
1.16\left(\mathrm{~d}, 6 \mathrm{H}, \mathrm{CH}_{3}\right), 7.11- \\
7.66(\mathrm{~d}, 4 \mathrm{H}, \mathrm{Ar}- \\
\mathrm{H}), 2.68(\mathrm{~m}, 1 \mathrm{H}, \mathrm{C}- \\
\mathrm{H}), 7.98(\mathrm{~s}, 1 \mathrm{H}, \mathrm{C}- \\
\mathrm{H}) 7.56(\mathrm{~s}, 1 \mathrm{H}, \mathrm{Ar}- \\
\mathrm{H}), 7.25-7.43(\mathrm{~m}, 3 \mathrm{H}, \mathrm{Ar}- \\
\mathrm{H})\end{array}$ \\
\hline
\end{tabular}

The graphs are plotted between fixed conc. of the synthesized Schiff bases and different conc. (0$10 \mathrm{mM})$ of $\beta-C D$. The graphs show that solubility of the compounds in aqueous medium enhance linearly as a function of the concentration of $\beta$-cyclodextrin up to $6^{\text {th }}$ point followed by a slight decline. 


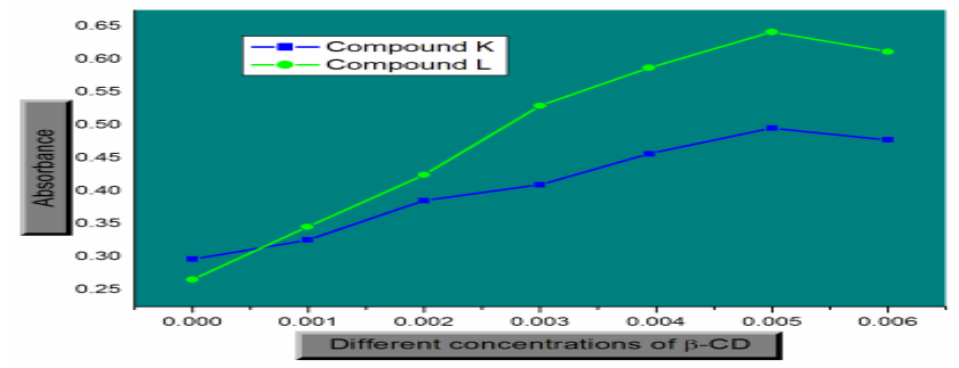

Fig. 1: Phase solubility study of the synthesized compounds

This concludes that the concentration at $6^{\text {th }}$ point is the suitable concentration for getting the higher yield of inclusion complex. Nice correlations have been obtained for plots of $1 / \Delta \mathrm{A}$ verses $1 /[\beta-\mathrm{CD}]_{\mathrm{o}}$. The plots are maintaining good linearity with a correlation coefficient (r) close to unity (Table 4)which supports the presumed $1: 1$ stoichiometry of complexation [21].

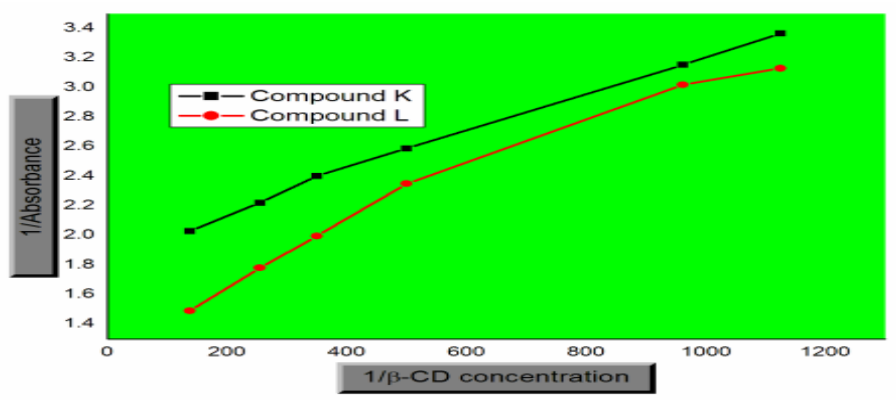

Fig. 2: Plot of inverse absorbance against inverse concentration of $\beta$ - cyclodextrin

The equilibrium constants $(\mathrm{K})$ have been calculated from the above inverse plots (Fig.2) for the compounds $\mathrm{K}$ and $\mathrm{L}$ and are found to be 857.8 and $748 \mathrm{M}^{-1}$ respectively(Table-4) .

Table 4: Thermodynamic stability constant and free energy change of inclusion complexes

\begin{tabular}{|l|l|l|l|l|}
\hline SI No. & $\begin{array}{c}\text { Inclusion complex of } \\
\text { Compound }\end{array}$ & $\begin{array}{l}\text { Equilibrium } \\
\text { Constant K } \\
\text { in M }^{-1}\end{array}$ & $\begin{array}{l}\square \mathbf{G}= \\
\mathbf{2 . 3 0 3 R T l o g} \mathbf{K} \\
\Delta \mathrm{G}(\mathrm{kJ} / \mathrm{mol})\end{array}$ & $\begin{array}{l}\text { Correlation } \\
\text { coefficient(r) }\end{array}$ \\
\hline $\mathbf{1}$ & I.C.K & 857.8 & -16.846 & 0.9987 \\
\hline $\mathbf{2}$ & I.C.L & 748 & -16.505 & 0.9756 \\
\hline
\end{tabular}

As the values are falling within ideal range $\left(100-1000 \mathrm{M}^{-1}\right)$, the synthesized complexes are having significant stability[22]. The displacement of energy rich water molecule by the hydrophobic guest molecule is the main driving force for these inclusion complex formation[23]. Negative values of free energy changes of inclusion complexes (Table-4) show that the host-guest interaction is spontaneous and thermodynamically feasible. The antibacterial study report reveals that the compounds are more effective towards bacterial strains after insertion into the cavity of $\beta$ - cyclodextrin. The promising antibacterial activity of the compounds may be due to increased solubility and enhanced stability after inclusion complex formation. It is also found that the Compound L (nitro furfural substituted Schiff base) is more potent towards bacterial pathogens as compared to Compound K (Fig.3,4). Both the compounds (K and L) show a good activity towards the three fungal organisms. The antifungal behavior of the compounds noticeably enhanced after entering in the cavity of $\beta$ cyclodextrin which is ascertained from the zone of inhibition (Table-5).

Table 5: Anti fungal activities of the compounds and complexes

\begin{tabular}{|c|c|c|c|}
\hline & A. Fumigatus & A. Niser & C.Albicans \\
\hline Compound/Complex & \multicolumn{2}{|c|}{ Zone of Inhibition in mm } \\
\hline Compound K & 12 & 08 & 07 \\
\hline I.C.K & 15 & 11 & 11 \\
\hline Compound L & 13 & 09 & 06 \\
\hline I.C.L & 17 & 13 & 09 \\
\hline Fluconazole(control) & 30 & 25 & 15 \\
\hline
\end{tabular}

Similarly the antioxidant potential data of the synthesized compounds before and after encapsulation exposed the fact that the free radical scavenging nature of Schiff bases enhanced predominantly after 
encapsulation (Table-6). Between compound $\mathrm{K}$ and L,the latter shows a considerable radical scavenging activity which may be due to presence of electron withdrawing nitro group in the compound.

Table-6: Antioxidant activities of compounds and their inclusion complexes

\begin{tabular}{|l|l|l|l|}
\hline Compound/Complex & Conc. $(500 \mu \mathrm{g} / \mathrm{ml})$ & Conc. $(100 \mu \mathrm{g} / \mathrm{ml})$ & $\%$ of increase \\
\hline Compound-K & 35.6 & 26.8 & 31.46 \\
\hline Inclusion with $\beta-C D$ & 46.8 & 33.6 & 25.37 \\
\hline Compound-L & 38.7 & 27.5 & 25.06 \\
\hline Inclusion with $\beta-C D$ & 48.4 & 34.6 & 25.81 \\
\hline Ascorbic acid & 90.00 & 74.30 & \\
\hline
\end{tabular}

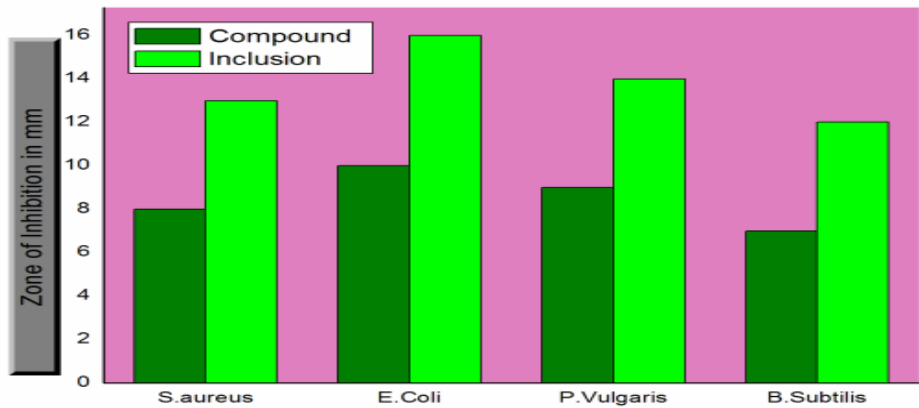

Fig. 3: Antibacterial activities of compound $\mathrm{K}$ and its inclusion complex

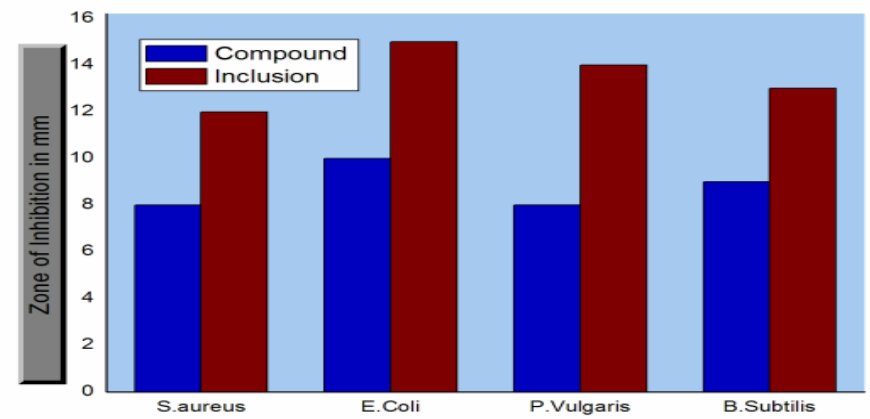

Fig. 4: Antibacterial activities of compound $L$ and its inclusion complex

\section{Conclusion}

The research work successfully synthesized inclusion complexes of Schiff bases with $\beta$ - cyclodextrin. The results of research concludes that the formation of inclusion complex of the synthesized compounds is the most appropriate mechanism to enhance the solubility, stability and the pharmacological activity in comparision to their respective compounds.

\section{References}

[1]. D.Wang, D.Y. Sheng, F.Qin, L. Fang, and P.Gong, synthesis and in vitro antiviral activities of some new 2-arylthio methyl-4tertiaryamino methyl substituted derivatives of 6-bromo-3-ethoxycarbonyl-5-hydroxy indoles, Chinese chemical letters,15(1),2004, 19-22.

[2]. D.S. Meht,KH. Sikotra, and HV. Shah, Synthesis and biological screening of some new indole derivatives, Ind J Chem,44(B), 2005,2594-2597.

[3]. T. Chandra, N. Garg, and A. Kumar, synthesis and anti-inflammatory activity of indole derivatives, Int J chem Tech Res,2(3),2010,762-773.

[4]. P. Thirumurugan,S. Mahalaxmi, and P.T. Perumal, synthesis and anti-inflammatory activity of indole derivatives, J chem sci,122(16),2010,819-832.

[5]. S.N. Pandeya, P. Yogeeswari, D. Sriram, andG. Nath,G synthesis and antimicrobial activity of N-Mannich bases of 3-N'sulphadoximinoisatin and its methyl derivatives, Boll Chim Farm,137,1998, 321-324.

[6]. N. Arumugam, R. Raghunathan,A.I. Almansour, and U. Karama, An efficient synthesis of highly functionalized novel chromeno[4,3-b] pyrroles and indolizino[6,7-b] indoles as potent antimicrobial and antioxidant agents, Bioorg Med Chem Lelt,22,2012, 1375-1379.

[7]. N. Karali, A. Gursoy, F.Kandemirli, N.Shvets, F.B.Kaynak,F,S. Ozbey, V.Kovalishyn, and A. Dinoglo, synthesis of 5-nitro-1H indole-2,3-dione-3-thiosemicarbazones and its 1-morpholinomethyl derivatives, Bioorg Med Chem,15,2007,5888.

[8]. A. Kamal,Y.V. Srikanth, M.N. Khan,T.B. Shaik, and M. Ashraf, synthesis of 3,3-diindolyl oxyindoles efficiently catalysed by $\mathrm{FeCl}_{3}$ and their invitro evalvation for anticancer activity. Bioorg Med Chem Lelt,20,2010, 5229-5231. 
[9]. J.K. Tripathy, and S.Panda, Thermodynamic and spectral studies of inclusion complexes of substituted indole derivatives with $\beta$ cyclodextrin, Asian J chem,23,2011,1631-1635.

[10]. B.Yang, J.Lin, Y.Chen, andY. Liu, Artemether/hydroxypropyl- $\beta$-cyclodextrin host-guest system : characterization, phase solubility and inclusion mode, Med Chem,17,2009,6311-6317.

[11]. S.Panda, and R. Sahu, studies on inclusion complex of 3-(2-chlorophenyl)4-methyl-2-thiocarbamoyl-3,3a-dihydro pyrazolo[3,4c], Am J Adv Drug Delivery,1(5),2013,1-9.

[12]. J. Szetjli, Downstream processing using cyclodextrins, TIBTRCH,7,1993,171-174.

[13]. R. Sahu, P. K. Das, and B. Garnaik, Exploration of Spectral, Thermal, Antibacterial and Antioxidant Activities of newly synthesized inclusion complexes of $\mathrm{N}$-(3-Phenylallylidine) and $\mathrm{N}$-(3-isopropylbenzylidene)-(1, 3, 4) Thiadiazino[6, 5b]Indole-3amine with $\beta$-CD, Der pharma Chemica,8, 2016,176-84.

[14]. T. Higuchi, and KA. Conners, phase solubility techniques, Adv Anal Chem Instrum,4,1965,117-212.

[15]. S.Panda,S.nayak, inclusion complex of acridone and its semicarbazone derivatives with $\beta$-Cyclo Dextrine a thermodynamic spectral and anitimicro bial study, Asian J Res Chem,2(4),2009,539-543.

[16]. H.A. Benesi, and JH. Hilderband, A Spectrophotometric investigation of the interaction of iodine with Aromatic hydrocarbons, J Am Chem Soc, 71,1999,2703-2707.

[17]. S. Nayak, S.Panda, P.Panda, and M. Padhy, studies on acridone derivatives with and without inclusion complex formation with $\beta$ CD, Bul chem com,42(2),2010,147-152.

[18]. V.R. Bollela, DN.Sato. and B.Fonseca, McFarland nephelometer as a simple method to estimate the sensitivity of the polymerase chain reaction using Mycobacterium tuberculosis as a research tool, Braz J Med Biol Res,32,1999,1073-1076.

[19]. P. Mukherjee, and K.K. Raghu, Effect of temperature on antagonistic and bio-control potential of Trichoderma sp. on Sclerotium rolfsii. Mycopathologia,139, 1997,151-155.

[20]. M. Tagashira, and Y. ohtake,Y. A new antioxidative 1,3-benzodioxide from Melissa officinals, Planta Med,64,1998,555-558.

[21]. S. Hazra, and G.S. Kumar,Physicochemical properties of inclusion complexes of Sanguinarine with natural cyclodextrins: Spectroscopy, Calorimetry and NMR studies, RSC Advances,5,2015,1873-1882.

[22]. J. Szetli, Molecular entrapment and release properties of drugs by Cyclodextrins controlled drug bioavailability, Wiley interscience,Newyork,3,1985,365-420.

[23]. J. Szetzli, Introduction and general overview of Cyclodextrin Chemistry, Chem Rev,98,1998,1743-1753. 